\title{
The Study on Chinese Rural-urban Income Gap Forecast
}

\author{
Zhao Zhongwei ${ }^{1, *}$ \\ ${ }^{1}$ School of Economics \& Management, Harbin Engineering University \\ 150001, Harbin (China); \\ zzw961@163.com
}

Keywords: Rural-urban income gap; Income sources; Regression analyze

\begin{abstract}
This paper simulates the income curve with SPSS statistics software on the basis of analyzing 1978-2012 Chinese urban and rural income data. The result indicates that the rural-urban income gap will expand further in the future and the rural-urban income ratio will reach 3.81:1 in 2020 according to the existing development trend. The study in this paper also indicates that there is a close correlation between the income source and income disparity. From the angle of income source this paper finds the main factors influencing the urban and rural income gap by the method of regression analysis and gives some pertinent suggestions to narrow the rural-urban income gap.
\end{abstract}

\section{INTRODUCTION}

The income disparity is one of the main standards to measure social justice. Rural-urban gap beyond normal limit not only affects consumption, but also affects the social structure coordinated development and the social stability. Therefore, we must take Chinese rural-urban gap seriously and make great efforts to narrow the income gap of the urban and rural residents step by step, realizes coordinated development of economic and social in city and countryside, and promotes Chinese sustainable development strategy to be carried on smoothly as planned ${ }^{[1]}$.

\section{DESCRIPTION OF CHINESE RURAL AND URBAN INCOME GAP}

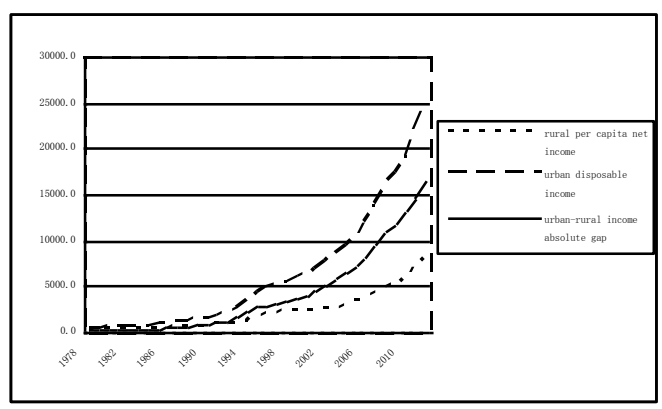

Figure. 1 Trend of rural-urban income absolute gap

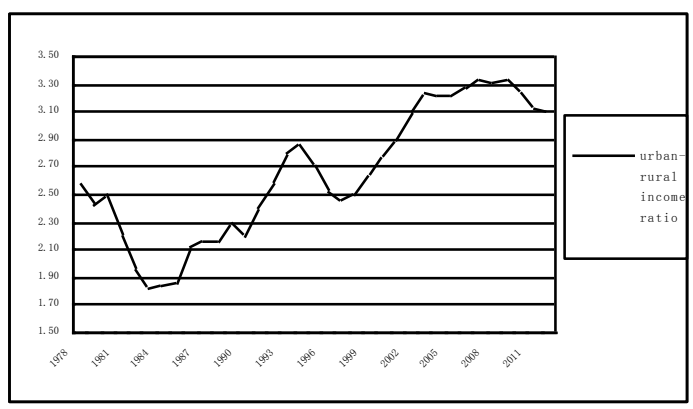

Figure. 2 Trend of rural-urban income ratio

The income gap between urban and rural residents can be seen as described in Figure 1, 1978-2012, the income of Chinese urban and rural residents all have substantial growth that disposable income of urban households at an average annual rate of $13.38 \%$, the per capita net income of rural households at an average annual rate of $12.76 \%$. There is an overall expansion trend of the absolute income gap between the two types of residents.

Figure 2, from the view of urban and rural incomes ratio, since the beginning of the reform and opening up, Chinese income gap between urban and rural residents experienced the process of a expansion after an, narrowing then another expansion after an narrow: 1978-1985, with the rural economic system reform, the income ratio of urban and rural residents reduced to 1.86 in 1985 from 2.57 in 1978; 1986-1994, with the focus transferring from rural to urban reform, accelerated urban 
economic development obviously, a remarkable increase in urban income, the income gap ratio between urban and rural residents tended to expand, rose to 2.86 in 1994, exceeded the initial stages level of the reform and opening up. Since 1995, with the rise in agricultural products price, and rural income increased, there was a re-narrowing between urban and rural income ratio, but expanded evident again after 1997, for the year 2001 as 2.90, 2002 3.11, and 2003 expanded to 3.23. From the year 2004, although the government took many measures to benefit the peasants, the rural-urban gap ratio has also remained at a relatively high level as 3.10-3.31. If taking the non-monetary urban income factors, such as housing, education, medical care, social security, social welfare into account, the income gap between urban and rural residents might be much higher ${ }^{[2]}$

\section{TREND FORECAST OF THE RURAL-URBAN INCOME GAP}

Establishment of forecast model. In order to forecast the trend of Chinese income gap, this article uses the SPSS curve regression carrying on the forecast analysis. According to the urban and rural income data in China Statistical Yearbook 1978-2012, using the linearity function, quadratic function, the exponential function and all the other functions to simulate curve separately comes with the actual data curve to carry on the contrast. We list better results among all the functions as follows:

Table 1 Result of SPSS simulating urban income curve

\begin{tabular}{lllllllll}
\hline $\begin{array}{l}\text { MODEL: MOD_1. } \\
\text { Independent: Time }\end{array}$ & & & & & & & \\
\hline Dependent & Mth & Rsq & d.f & F & Sigf & b0 & b1 & b2 \\
\hline $\mathbf{U t}$ & LIN & 0.818 & 33 & 148.34 & 0.00 & -4421.8 & 592.842 & \\
\hline $\mathbf{U t}$ & QUA & 0.980 & 32 & 764.66 & 0.00 & 2059.42 & -458.17 & 29.1948 \\
\hline $\mathbf{U t}$ & COM & 0.991 & 33 & 3453.16 & 0.00 & 301.953 & 1.1378 & \\
\hline $\mathbf{U t}$ & EXP & 0.991 & 33 & 3453.16 & 0.00 & 301.953 & 0.1291 & \\
\hline
\end{tabular}

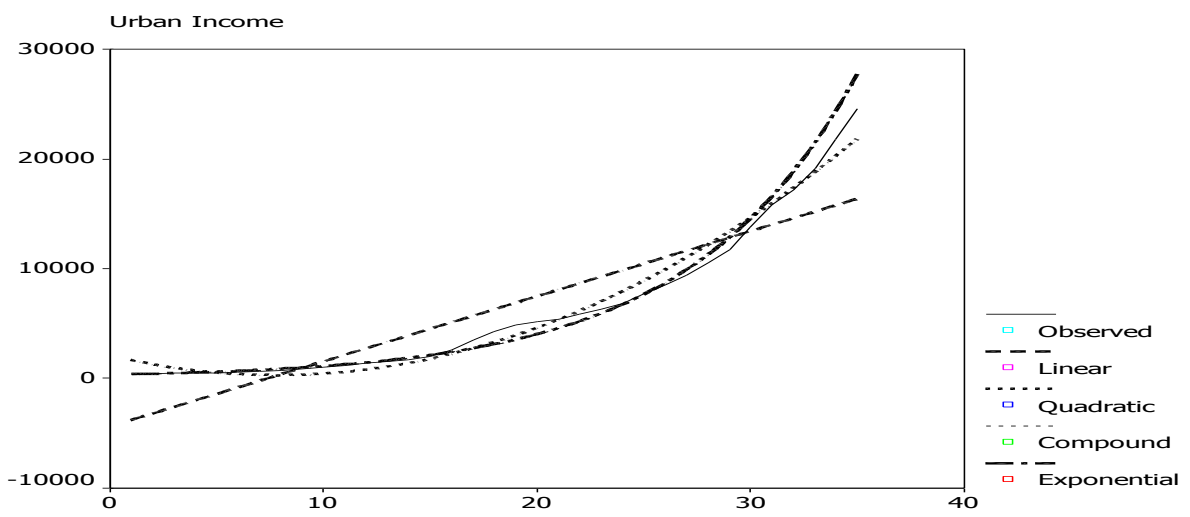

Figure. 3 SPSS simulating urban income curve 
Table 2 Result of SPSS simulating rural income curve

\begin{tabular}{lllllllll}
\hline $\begin{array}{l}\text { MODEL: MOD_1. } \\
\text { Independent: Time }\end{array}$ & & & & & & & \\
Dependent & Mth & Rsq & d.f & F & Sigf & b0 & b1 & b2 \\
\hline Rt & LIN & 0.827 & 33 & 157.22 & 0.00 & -1198.4 & 182.015 & \\
\hline Rt & QUA & 0.963 & 32 & 418.77 & 0.00 & 622.872 & -113.33 & 8.2040 \\
\hline Rt & COM & 0.985 & 33 & 2161.75 & 0.00 & 152.865 & 1.1204 & \\
\hline Rt & EXP & 0.985 & 33 & 2161.75 & 0.00 & 152.865 & 0.1137 & \\
\hline
\end{tabular}

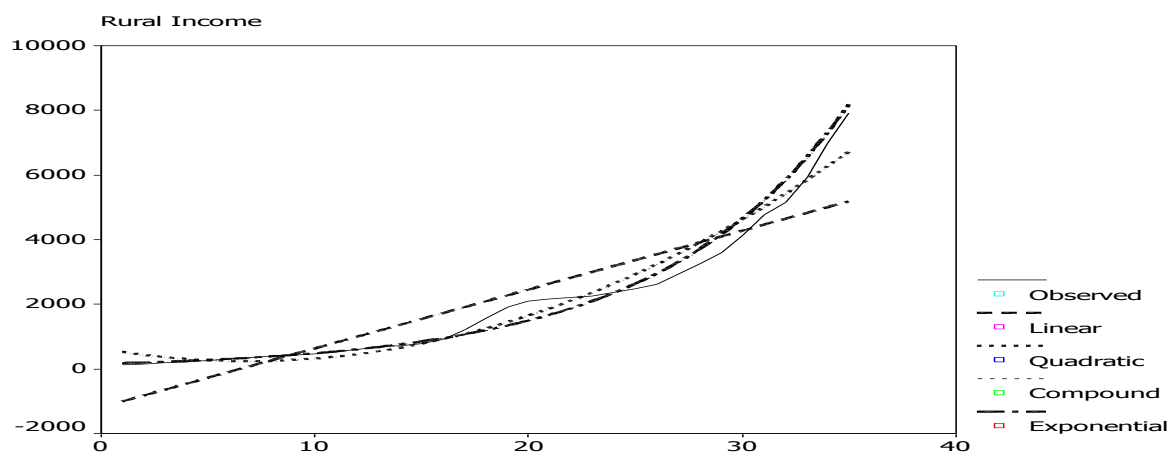

Figure. 4 SPSS simulating rural income curve

We can see from Table 1, simulates the urban income curve, compound and exponential functions fit better, $\mathrm{R}^{2}=0.991$. We can find out that their curves are very close to the actual observation curve from Figure 3. Therefore this article used the compound function model to carry on the simulation (actually, the result of exponential function is very close to the result of compound function). The compound function model is:

$$
\boldsymbol{U}_{t}=b_{0} \times b_{1}^{x}=301.953 \times 1.1378^{(t-1978)}
$$

$\boldsymbol{U}_{t}$ : Per capita disposable income of urban residents in t year

From table 2, obviously, the fit goodness of the compound and the exponential are still both very good to actual rural income observation data, their fit goodness $\mathrm{R}^{2}=0.985$. In order to receive consistently result with urban income, we also choose the compound function to forecast the countryside inhabitant's future income. The compound function model is:

$$
\boldsymbol{R}_{t}=b_{0} \times b_{1}^{x}=152.865 \times 1.1204^{(t-1978)}
$$

$\boldsymbol{R}_{t}:$ Per capita net income of rural residents in t year

Forecast of Chinese rural-urban residents income ratio. According to the two simulation functions above, disposable income of urban residents will reach 77763 Yuan and 20293 Yuan of the per capita net income of rural households in 2020. Although there maybe some error in the forecast income absolute figure limited to the model selection and research methodology, we can eliminate deviations with the ratio method. So the income gap ratio we forecasted should be acceptable in a certain error range. According to the existing development condition, Chinese city and countryside income gap ratio will increase to 3.81: 1 in 2020 (if we choose the exponential function, we can also get the similar result as 3.83:1), the city and countryside income disparity will expand further. So estimating from the present development tendency, it is an extremely arduous duty to reduce the income gap between urban and rural residents. 


\section{REASON ANALYSIS OF CHINESE CITY AND COUNTRYSIDE RESIDENTS INCOME GAP}

Establishment of the evaluating model. As there maybe plentiful and variable reasons for the income disparity, finding the main reasons through the quantitative analysis is the first question that must be solved $^{[3]}$. This article considered every various aspect factor, then choose city and countryside wages ratio, business income ratio, property income ratio and shift income ratio four indicators, analyzes their importance to the income gap from the angle of income source by the regression analysis method, discovers the major factors to provide the policy basis for reducing the income gap ${ }^{[4]}$. Concrete results as Table 3 and Table 4.

Table 3 Cumulative contribution of four indicators to rural-urban income ratio

\begin{tabular}{lllll}
\hline Model & $\mathrm{R}$ & $\mathrm{R}$ Square & Adjusted R Square & Std. Error of the Estimate \\
\hline 1 & 0.853 & 0.728 & 0.637 & 0.21997 \\
\hline
\end{tabular}

a Predictors: (Constant), wages ratio, business income ratio, shift income ratio, property income ratio

Table 4 Respective contribution of four indicators to rural-urban income ratio

\begin{tabular}{|c|c|c|c|c|c|c|}
\hline & & Unstandardized Coefficients & & $\begin{array}{l}\text { Standardized } \\
\text { Coefficients }\end{array}$ & $\mathrm{T}$ & Sig. \\
\hline \multicolumn{2}{|c|}{ Model } & B & Std. Error & Beta & & \\
\hline \multirow[t]{5}{*}{1} & Constant & 0.450 & 0.805 & & 0.560 & 0.038 \\
\hline & wages & 0.207 & 0.089 & 0.642 & 2.337 & 0.044 \\
\hline & business & 4.388 & 1.197 & 0.974 & 3.667 & 0.005 \\
\hline & shift & 1.168 & 0.045 & 0.373 & 1.626 & 0.029 \\
\hline & property & $1.895 \mathrm{E}-02$ & 0.027 & 0.226 & 0.700 & 0.042 \\
\hline
\end{tabular}

al-urban income ratio

Analysis of evaluating results. Can be seen from Table 3 and Table 4: According to the linear regression model, city and countryside wages income ratio, business income ratio, shift and property income ratio are the major factors for the income gap ratio, four factors can explain $85.3 \%$ of the income gap reason. Among the four factors, business income ratio is the most important influence factor to income gap, next for shift income ratio and wages ratio, the property income ratio is not as important as the other three factors to the income disparity.

At present, the main contradictory to the income gap rests with the rural low-income level. As above, we should put emphases on increasing the rural business and wages income as well as the shift income, at the same time pay attention to the reasonable policy arrangement to prevent the further income gap expanding.

\section{Suggestions for reducing Chinese city and countryside income disparity}

Enlarging the countryside human capital investment. Different human capital investment brings different human resources quality, affects the city and countryside economy development speed and level, has formed the city and countryside income assignment disparity. What's more, in turn, the disparity of city and countryside economy level, also is affecting the economy development by the different reacting force, has enlarged the city and countryside human capital investment disparity, intensified the city and countryside income assignment disparity ${ }^{[5]}$. Therefore, in the long views, enlarging the countryside human capital investment is not only relating our country countryside area labour force quality enhancement, but also relating the rural economy long term development and the growth potential, at the same time, it has vital significance to reduce the city and countryside income disparity out of question. 
China is in the process of reducing income disparity and eliminating the countryside poverty. Increasing the rural income directly through many kinds of economy policies can only alleviate the impoverished condition for a while, can not solve the rural economy society sustainable development problem fundamentally ${ }^{[6]}$. The policy meaning we may obtain through the conclusion above is: To reduce the city and countryside income disparity and achieve the urban and rural common enrichment goal, we must develop the countryside education vigorously, specially must enhance the education level in countryside underdevelopment and low-income area.

Perfecting labour market environment. It is very important that improves the countryside exterior market environment to reduce the income disparity, especially improves the labour force market environment, enables more low-income people to be engaged in the non-agricultural employment outside the countryside and obtains wages income. We should also advance the small cities construction in respect that small cities are the advantageous place for rural enterprise and important base to the rural labour force ${ }^{[7]}$.

Looked from the countryside interior, the improvement of employment labour market is helpful to the labour income realization and enhance labour income proportion, then reduces the income disparity. At present, the farmer non-agricultural employment has become the main source of increasing income. Therefore, developing the rural enterprise and individual private sector is an effective way to increase the peasants' income. We should profit from the experience of coastal province that develops the labour-intensive small and media scale rural enterprise vigorously when puts attention to the development of large enterprise group, fully displays the function of rural enterprise to absorb in the rural labour force employment.

Strengthening the policy support. Business income is the main source of the peasants' income. We must take actions that suit local circumstances to readjust agriculture and the rural economy structure. It's very important that making full use of favourable factors to develop characteristic superiority agriculture. At the same time we must create the condition positively to guide the peasants to be engaged in secondary industry and tertiary-industry management, increasing the peasants' business income. We should promote the development of the individual private enterprise, and so on as the non-state economy development through financial service as credit, mortgage guarantee, as well as the reasonable tax revenue measure. We must break the monopolization of business project investment and encourage the folk investment, support the development of the countryside individual private sector and large industrial enterprise.

Strengthening the transfer payment function of the government. In the funds investment, we may act according to the overseas experience, by center government investment primarily, all levels of governments finance necessary, pays through all levels of governments' transfer payments to realize the underdeveloped area countryside compulsory education. Certainly, besides the education investment, the government transfer payment may similarly play an important role in the public goods investment and countryside infrastructure construction, thus avoids the trend of the income disparity expanding unceasingly.

\section{DISCUSSION AND CONCLUSION}

In summary, this paper forecasted Chinese urban and rural income gap, adopted mainly regression analysis techniques. The research results are in line with the actual situation in China. Urban and rural income gap is a dynamic, highly difficult research topic. The research in this paper is only an exploratory attempt. The author will attempt to do further study by improving research technique and exploring new research way(This paper is supported by the Heilongjiang Province project GZ11D208 and the fundamental research funds for the central universities). 


\section{REFERENCES}

[1] Zhang Song-song, 2014, Chinese city and countryside inhabitant income disparity change characteristic and countermeasure. Shanxi Economy Review,16, 18-22.

[2] Huang Zu-hui, 2009, City and countryside income disparity question research. Zhejiang University Journal, 17, 122-131.

[3] Wang Bao-hai, 2009, Our country average per person income target discrimination. Statistics And Consultation, 14, 22-29.

[4] Chen Guang, 2012, City and countryside income equality and government policy choice. Management Research, 15, 219-222.

[5] Ravi Kanbur, 2001, What differences do polarization measures make? Application to China. The Journal of Development Studies, 13, 86-90.

[6] Lee.J., 2000, Changes in the source of China's regional disparity. China economic review, 11, 232-245.

[7] Shorrocks.A.F.(1984) Disparity decomposition by population subgroups[J]. Economics(16), 1369-1385.

[8] T.L.Satty. The Analytic Hierarchy Process[J], McGraw Hill, Inc, 1980, (7):6-9

[9] McHarg I. Design with Nature [M]. New York: Nature History Press, 1969: 6-9

[10] Wen-lin. A study on the effectiveness of the most advantageous tendering method in the public works of Taiwan.[J] International J of Project Management, 2006, (24): 431-437 